\title{
Effect of sputum induction on arterial oxygen saturation and spirometry in HIV-infected patients
}

\author{
T.R. Leigh*, K. Kirby**, B.G. Gazzard+, J.V. Collins*++
}

Effect of sputum induction on arterial oxygen saturation and spirometry in HIVinfected patients. T.R. Leigh, K. Kirby, B.G. Gazzard, J.V. Collins. CERS Journals Ltd 1994.

ABSTRACT: We wanted to study the effect of sputum induction on forced expiratory volume in one second $\left(\mathrm{FEV}_{1}\right)$ and on oxygen saturation in normal controls, asymptomatic human immunodeficiency virus (HIV)-seropositive individuals, and HIV-seropositive patients under investigation for suspected Pneumocystis carinii pneumonia (PCP).

Over a five month period, sputum induction with ultrasonically nebulized $3 \%$ saline was performed on 110 HIV-seropositive patients with suspected PCP, 10 asymptomatic HIV-seropositive patients, and 15 normal controls. Oxygen saturation (peak, trough and change in oxygen saturation $\left(\Delta \mathrm{O}_{2}\right)$ ) was measured throughout the procedure using pulse oximetry, and these results compared with the chest radiograph and the final pulmonary diagnosis. In addition, the effect of sputum induction on $\mathrm{FEV}_{1}$ was measured in the 15 control subjects and 10 asymptomatic HIV-seropositive patients.

Compared with bronchoalveolar lavage, sputum induction had a diagnostic sensitivity for PCP of $76 \%$. Chest radiography was $79 \%$ sensitive, and had specificity of $83 \%$. Patients with PCP had lower peak and trough oxygen saturation values compared with the non-PCP group (mean peak 95 vs $97 \%$; mean trough 88 vs $91 \%$ ), and greater falls in $\mathrm{O}_{2}$ saturation during the procedure (mean $\Delta \mathrm{O}_{2} 7.6$ vs $5.5 \%$ ). One subject desaturated to $76 \%$, requiring supplemental oxygen. Sputum induction caused significant but temporary falls in FEV both in control and HIVseropositive groups (mean maximum fall in $\mathrm{FEV}_{1} 10.4$ vs $12.5 \%$ )

We conclude that although sputum induction causes significant falls in oxygen saturation and $\mathrm{FEV}_{1}$, it remains sensitive and safe, and provides a useful alternative to bronchoscopy for the diagnosis of PCP.

Eur Respir J., 1994, 7, 453-458.
Depts of *Respiratory Medicine, and **Physiotherapy, and +HIV Services, Dept, Chelsea and Westminster Hospital, London, UK. ++Royal Brompton National Heart and Lung Hospitals, London, UK.

Correspondence: T.R. Leigh

Dept of Thoracic Medicine

Royal Free Hospital

Pond Street

London NW3 2QG

UK

Keywords: Human immunodeficiency virus Pneumocystis carinii

pulse oximetry

spirometry

sputum induction

Received: January 221993

Accepted after revision October 201993
Pneumocystis carinii pneumonia (PCP) remains the index diagnosis in more than $65 \%$ of patients presenting with the acquired immune deficiency syndrome (AIDS) [1], and still carries a significant mortality, which varies depending on the severity of illness at the time of presentation, and the experience of individual institutions for treating the condition [2]. Because most patients with PCP are unable to produce sputum spontaneously, use of fibreoptic bronchoscopy with bronchoalveolar lavage, and, more recently, sputum induction (SI) are frequently necessary in order to obtain specimens from which the organism can be identified, and thereby to confirm the diagnosis [3]. Although the procedure of sputum induction, which involves the inhalation of a mist of nebulized hypertonic saline, has been shown to be a relatively safe and sensitive technique for diagnosing PCP in AIDS patients [4], there have been some isolated reports of complications, such as hypoxaemia [5] and pleural effusion [6], in a small number of cases.

Since exercise-induced arterial oxygen desaturation has been used as a screening test for identifying PCP in high- risk symptomatic patients [7], this study was performed to document changes caused by sputum induction in spirometry and arterial oxygen saturation in normal controls, asymptomatic human immunodeficiency virus (HIV)-seropositive patients, and patients undergoing investigation for suspected PCP. The study was also used to determine the relationship, if any, between oxygen saturation, chest radiograph appearances, and the resulting final pulmonary diagnosis.

\section{Patients and methods}

Over a five month period, sputum induction was performed on three separate groups of subjects (table 1). The first group consisted of 110 male HIV-seropositive patients presenting with respiratory or other symptoms suggestive of active PCP (mean age 38 yrs, range 23-70 yrs; mean CD4 count $69 \times 10^{6} \cdot l^{-1}$, range $\left.1-551 \times 10^{6} \cdot l^{-1}\right)$. Of these 110 patients, 43 were regular smokers, 36 had previously had $\mathrm{PCP}$, and 72 were receiving regular 
Table 1. - Details of the three groups used in the study

\begin{tabular}{cccccc}
\hline Group & $\begin{array}{c}\text { Age* } \\
\text { yrs }\end{array}$ & $\begin{array}{c}\text { CD4* } \\
\times 10^{6} \cdot l^{-1}\end{array}$ & Rx & $\begin{array}{c}\text { Smoker } \\
\text { Y/N }\end{array}$ & $\begin{array}{c}\text { PCP } \\
\text { Y/N }\end{array}$ \\
\hline $\begin{array}{c}\text { HIV-symptomatic } \\
\text { n=110 }\end{array}$ & $38(23-70)$ & $69(1-551)$ & $\begin{array}{c}54 \text { AZT } \\
18 \text { DDI }\end{array}$ & $43 / 67$ & $36 / 74$ \\
$\begin{array}{c}\text { HIV-asymptomatic } \\
\text { n=10 }\end{array}$ & $30(20-42)$ & $561(422-762)$ & - & $6 / 4$ & $0 / 10$ \\
$\begin{array}{c}\text { Control } \\
\text { n=15 }\end{array}$ & $26(20-36)$ & - & - & $0 / 15$ & $0 / 15$ \\
\hline
\end{tabular}

*: data presented as mean, and range in parenthesis. PCP: number of patients with a previous episode of Pneumocystis carinii pneumonia; AZT: patients receiving zidovudine therapy; DDI: patients receiving dideoxyinosine therapy; HIV: human immunodeficiency virus; Rx: therapy; Y: yes; N: no.

anti-retroviral therapy (54 taking zidovudine (AZT), and 18 taking dideoxyinosine (DDI)). The second group of subjects consisted of 10 asymptomatic, male HIVseropositive patients receiving no anti-retroviral medication, six of whom were smokers (mean age $30 \mathrm{yrs}$, range $20-42$ yrs; mean CD4 count $561 \times 10^{6} \cdot l^{-1}$, range $\left.422-762 \times 10^{6} \cdot l^{-1}\right)$. The third group consisted of 15 nonsmoking, healthy, male controls with low risk of HIVinfection (mean age $26 \mathrm{yrs}$, range 20-36 yrs). None of the subjects from any of the three groups were asthmatic, nor did they have a past history of chronic lung disease.

Written consent was obtained from all subjects prior to the study, which was approved by the Riverside East Ethics Committee.

\section{Sputum induction protocol and diagnosis of PCP}

Sputum induction was performed on all of the subjects from each of the three groups as described previously [4]. Subjects inhaled a mist of nebulized 3\% hypertonic saline delivered by a DeVilbiss Ultraneb 99 ultrasonic nebulizer for 20-40 min, consuming 30-50 ml of hypertonic saline. Gentle chest percussion physiotherapy was given when necessary to encourage sputum expectoration, and the procedure was continued until the subjects had produced a sputum specimen of sufficient quality and quantity (as judged by the respiratory physiotherapist) for laboratory analysis. Patients from the symptomatic group who were found to be negative for $P$. carini on induced sputum went on to have fibreoptic bronchoscopy with bronchoalveolar lavage within four days of the sputum induction. All induced sputum and bronchoalveolar lavage specimens underwent routine microbiological examination including staining and culture for Mycobacteria species, and examination for the presence of $P$. carinii using both an indirect immunofluorescence stain (Northumbria Biologicals Ltd, Northumbria, UK), and Grocott's methenamine silver stain.

\section{Oximetry studies}

Throughout the sputum induction procedure, and for 2 min after completion, arterial oxygen saturation was measured continuously in all subjects from each of the three groups using a Minolta Pulsox-7 oxygen saturation monitor (DeVilbiss Health Care UK, Heston, Middlesex, UK). In each subject, values were obtained for the peak and trough oxygen saturation readings, representing, respectively, the highest and lowest oxygen saturation measurements obtained throughout the procedure. From these values the change in oxygen saturation $\left(\Delta \mathrm{O}_{2}\right)$ was calculated, being the difference between the peak and trough oxygen saturation values obtained with each subject. These three readings (peak, trough, and $\Delta \mathrm{O}_{2}$ ) were compared retrospectively with the final pulmonary diagnoses obtained in each patient, based on the results of microbiological investigations performed on induced sputum and, when available, bronchoscopy with bronchoalveolar lavage.

\section{Spirometry studies}

The effect of sputum induction on forced expiratory volume in one second $\left(\mathrm{FEV}_{1}\right)$ was studied in the 15 control subjects and the 10 asymptomatic HIV-seropositive individuals using a standard dry bellows spirometer (Vitalograph Ltd, Buckingham, UK), before sputum induction, and serially at $0,1,5,10$ and 15 min after completing the procedure. Each subject was given careful instruction on how to use the spirometer, with the best result of at least three attempts being recorded. Falls in $\mathrm{FEV}_{1}$ were recorded as a percentage of the baseline $\mathrm{FEV}_{1}$ value, which was expressed as a percentage of the predicted $\mathrm{FEV}_{1}$, from standard tables based on age and height.

\section{Chest radiography}

In addition to the sputum induction and bronchoalveolar lavage procedures, all of the 110 symptomatic patients underwent routine chest radiography prior to sputum induction. These radiographs were reported as being either "highly-suggestive" or "unlikely to be active" PCP, by an independent radiologist, who was blind to the final pulmonary diagnosis.

\section{Statistical analysis}

Statistical analysis of the CD4 data, oxygen saturation, spirometry, and radiography results was performed using the nonparametric Mann-Whitney U test. 


\section{Results}

Of the 135 sputum inductions performed, no patient or control subject developed side-effects sufficiently severe to require premature termination of the procedure, nor were there any early or late complications to sputum induction similar to those reported previously $[5,6]$. However, one patient from the symptomatic group, who was previously severely hypoxic on room air, and who subsequently proved to have PCP, was observed to desaturate down to a level of $76 \%$ at $5 \mathrm{~min}$ intervals throughout the sputum induction procedure, requiring intermittent short periods of supplementary oxygen to restore saturation levels to above $90 \%$. The main sideeffects noted were slight nausea with retching, and an unpleasant salty taste, although neither of these was particularly severe, and did not prevent the subjects from completing the sputum induction procedure.

\section{Diagnosis of PCP}

None of the induced sputum specimens from the control or asymptomatic HIV-seropositive groups were positive for $P$. carinii by either the Grocott or immunofluorescence stains. In the HIV-symptomatic group, however, 22 induced sputum specimens were positive for $P$. carinii, the remaining specimens were either negative for $P$. carinii (84) or equivocal (fewer than five cysts per slide seen on immunofluorescence) (4). Of the 88 patients with either negative or equivocal results, 31 subsequently underwent fibreoptic bronchoscopy with bronchoalveolar lavage (BAL), seven of which were found to be positive for $P$. carinii. Six of these had previously given negative results for $P$. carinii on induced sputum, the remaining subject having given an equivocal result. Of those subjects with induced sputum results negative for
$P$. carinii, but who failed or refused to have BAL, none went on to develop PCP during a 6 month follow-up period. All of these patients either recovered spontaneously from their respiratory illnesses, or responded to broad spectrum antibiotics (without anti-pneumocystis activity). Overall, therefore, 29 of the 110 symptomatic subjects were diagnosed as having PCP (22 on sputum induction alone), 76 were judged to be negative for PCP (see table 2), and a further five subjects, who recovered after receiving anti-pneumocystis chemotherapy, gave equivocal results for $P$. carinii (two after induced sputum alone). These results gave sputum induction a sensitivity of $76 \%$ for diagnosing PCP when compared with bronchoalveolar lavage.

The mean CD4 count of the asymptomatic HIVseropositive group was significantly higher than that of both the PCP and non-PCP symptomatic groups $\left(561 \times 10^{6} \cdot l^{-1}\right.$ vs $34 \times 10^{6} \cdot l^{-1}$ and $83 \times 10^{6} \cdot l^{-1}$, respectively; $\mathrm{p}<0.0001)$, whilst that between the PCP and non-PCP groups was not significantly different $(\mathrm{p}=0.13)$.

\section{Oximetry studies}

Throughout the sputum induction procedure, none of the control subjects developed oxygen saturation levels below 93\%, and changes in saturation were no greater than $4 \%$ in any of the subjects. Similarly, in the asymptomatic HIV-seropositive group, saturation values did not drop below $91 \%$ at any time, and change in saturation $\left(\Delta \mathrm{O}_{2}\right)$ was no greater than $4 \%$ in any subject. Although there was a wide range of peak and trough oxygen saturation values within the PCP and non-PCP groups (table 2 and fig. 1), both peak and trough saturation values were significantly lower in the PCP group compared with the non-PCP group (mean peak values 95 vs $97 \%$, respectively, $\mathrm{p}<0.03$; mean trough values 88 vs $91 \%$, respectively, $\mathrm{p}<0.002)$.

Table 2. - Mean CD4 counts, oxygen saturation values, and results of chest radiography for the different groups

\begin{tabular}{|c|c|c|c|c|c|}
\hline \multirow{3}{*}{ Groups } & \multirow{3}{*}{$\begin{array}{l}\text { CD4 count } \\
\times 10^{6} \cdot l^{-1}\end{array}$} & \multicolumn{3}{|c|}{ Oxygen saturation* } & \multirow{3}{*}{$\begin{array}{c}\text { Correct CXR } \\
\text { diagnosis } \\
\%\end{array}$} \\
\hline & & Peak & & $\Delta \mathrm{O}_{2}$ & \\
\hline & & $\%$ & $\%$ & $\%$ & \\
\hline $\begin{array}{c}\text { Controls } \\
n=15\end{array}$ & - & $97 \pm 0.33$ & $94 \pm 0.27$ & $3 \pm 0.27$ & - \\
\hline $\begin{array}{l}\text { HIV-pos asymptomatic } \\
\mathrm{n}=10\end{array}$ & 561 & $96 \pm 0.38$ & $94 \pm 0.46$ & $2.6 \pm 0.25$ & - \\
\hline $\begin{array}{c}\text { PCP } \\
n=29\end{array}$ & 34 & $95 \pm 0.66$ & $88 \pm 1.04$ & $7.6 \pm 0.7$ & 79 \\
\hline $\begin{array}{c}\text { Non-PCP } \\
n=76\end{array}$ & 83 & $97 \pm 0.28$ & $91 \pm 0.51$ & $5.5 \pm 0.45$ & 83 \\
\hline PCP vs non-PCP & & & & & \\
\hline $\mathrm{p}$ values & 0.13 & $<0.03$ & $<0.002$ & $<0.0005$ & \\
\hline HIV-pos asympt vs PCP & & & & & \\
\hline $\mathrm{p}$ values & $<0.0001$ & NS & $<0.001$ & $<0.0001$ & \\
\hline $\begin{array}{l}\text { HIV-pos asympt } v s \text { non-PCP } \\
\text { p values }\end{array}$ & $<0.0001$ & NS & $<0.04$ & $<0.0005$ & \\
\hline
\end{tabular}

*: mean \pm SEM. CXR: chest X-ray; pos: positive; $\Delta \mathrm{O}_{2}$ : change in oxygen saturation; Ns: nonsignificant. For further abbreviations see legend to table 1 . 


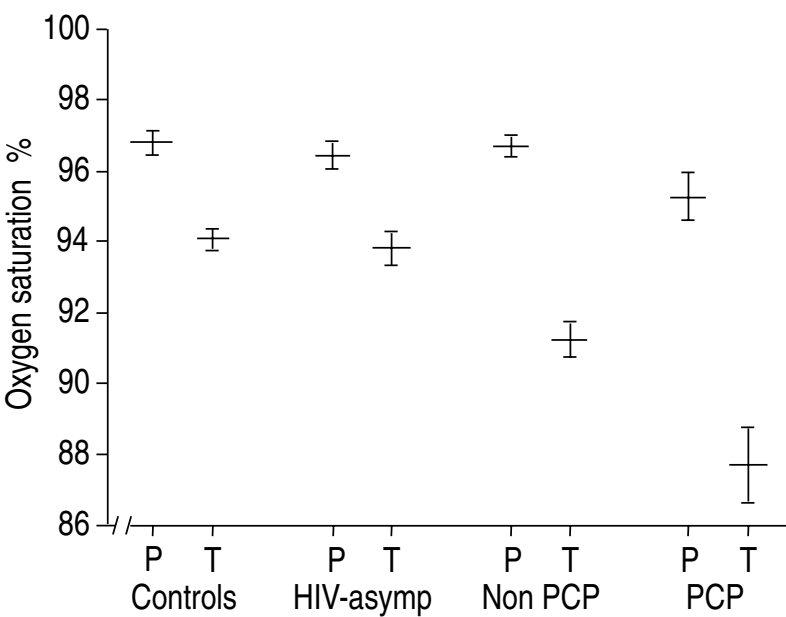

Fig. 1. - Values for peak and trough oxygen saturations in the four groups of subjects. Data are presented as mean \pm SEM. HIV: human immunodeficiency virus; PCP: Pneumocystis carinii pneumonia; asymp: asymptomatic. P: peak; T: trough.

Similarly, the fall in oxygen saturation $\left(\Delta \mathrm{O}_{2}\right)$ during sputum induction was significantly greater in the PCP group compared with the non-PCP group (mean $\Delta \mathrm{O}_{2} 7.6$ vs $5.5 \%$, respectively, $\mathrm{p}<0.0005)$. Compared with the asymptomatic HIV-seropositive group, peak oxygen saturation values were not significantly different from either the PCP or non-PCP groups. However, both the PCP and non-PCP groups had significantly lower trough oxygen saturation values $(\mathrm{p}<0.001$ and 0.04 , respectively), and significantly greater $\Delta \mathrm{O}_{2}$ values $(\mathrm{p}<0.0001$ and 0.0005 , respectively), when compared with the asymptomatic HIV-seropositive group. Oxygen desaturation during sputum induction was not specifically associated with any of the other non-PCP diagnoses, such as pulmonary Kaposi's sarcoma (two cases), Mycobacterium avium intracellulare infection (one case), or lymphoma (one case), nor was it associated with either the number of previous episodes of PCP, or previous smoking history. Similarly, there was no relationship between the severity of oxygen desaturation during sputum induction and the use of specific anti-retroviral therapy such as AZT or DDI.

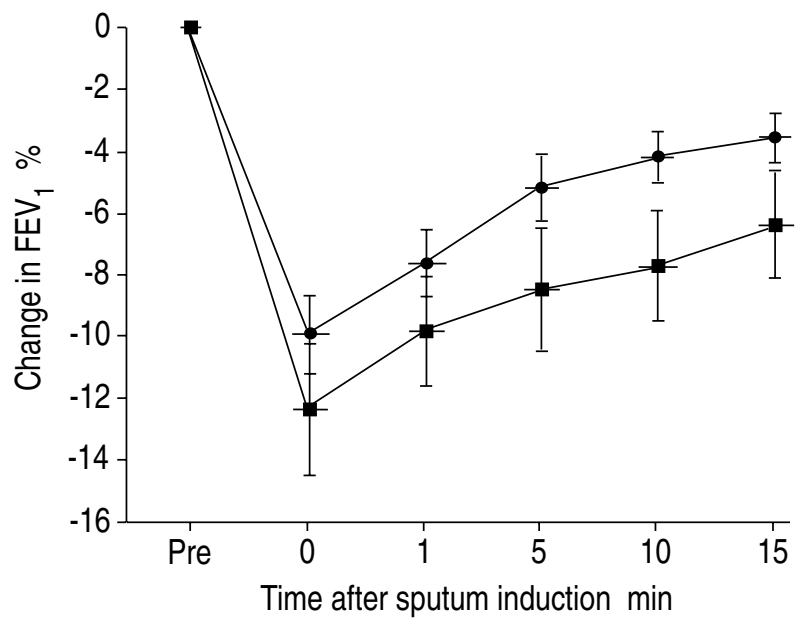

Fig. 2. - Percentage falls in FEV for 15 control and 10 asymptomatic HIV-seropositive patients before and after sputum induction. Data are presented as mean \pm sem. $\longrightarrow-$ : controls; - - - : HIVpositive asymptomatic. $\mathrm{FEV}_{1}$ : forced expiratory volume in one second; HIV: human immunodeficiency virus.

\section{Chest radiography}

In the PCP group, chest radiographs were correctly interpreted as being highly suggestive of active PCP in 23 of the 29 cases, giving a sensitivity of $79 \%$, but incorrectly diagnosed active $\mathrm{PCP}$ in 13 of 76 PCP-negative patients, resulting in a specificity of $83 \%$ and a negative predictive value for chest radiography of $91 \%$ (table 2). Both the peak and trough oxygen saturation values were significantly lower, and the fall in saturation $\left(\Delta \mathrm{O}_{2}\right)$ greater, in those patients with chest radiographs suggestive of PCP, compared with those patients with normal chest radiographs (mean peak values 95 vs $97 \%$, $\mathrm{p}<0.02$; mean trough values 88 vs $92 \%, \mathrm{p}<0.0001$; mean $\Delta \mathrm{O}_{2}$ values: 8 vs $5 \%, \mathrm{p}<0.0001$; respectively).

\section{Spirometry studies}

Despite a trend towards lower baseline $\mathrm{FEV}_{1}$ measurements in the asymptomatic HIV-seropositive group

Table 3. - Percentage falls in $\mathrm{FEV}_{1}$ for the control and asymptomatic HIV-seropositive groups

\begin{tabular}{|c|c|c|c|c|c|c|}
\hline \multirow[b]{2}{*}{ Group } & \multicolumn{6}{|c|}{ Time after sputum induction $\mathrm{min}$} \\
\hline & 0 & 1 & 5 & 10 & 15 & Max \\
\hline Control & 10.0 & 7.7 & 5.3 & 4.3 & 3.7 & 10.4 \\
\hline $\mathrm{n}=15$ & \pm 1.3 & \pm 1.1 & \pm 1.0 & \pm 0.8 & \pm 0.8 & \pm 4.7 \\
\hline $\mathrm{p}$ value & $<0.001$ & $<0.001$ & $<0.001$ & $<0.002$ & $<0.003$ & $<0.001$ \\
\hline HIV-pos & 12.4 & 9.9 & 8.6 & 7.8 & 6.5 & 12.5 \\
\hline $\begin{array}{c}\text { asympt } \\
n=10\end{array}$ & \pm 2.2 & \pm 1.8 & \pm 2.0 & \pm 1.8 & \pm 1.7 & \pm 2.1 \\
\hline $\mathrm{p}$ value & $<0.005$ & $<0.005$ & $<0.005$ & $<0.005$ & $<0.01$ & $<0.005$ \\
\hline \multicolumn{7}{|c|}{ Control vs HIV-positive asymptomatic } \\
\hline $\mathrm{p}$ value & 0.54 & 0.31 & 0.31 & 0.16 & 0.22 & 0.65 \\
\hline
\end{tabular}

Data are presented as mean \pm SEM. $\mathrm{p}$ values represent statistical significance versus baseline $\mathrm{FEV}_{1}$. Time 0 is immediately after sputum induction, $<0.5 \mathrm{~min} . \mathrm{FEV}_{1}$ : forced expiratory volume in one second. For further abbreviations see legends to table 1 and 2. 
compared with controls, there was no statistical difference between the two groups (mean baseline $\mathrm{FEV}_{1} 103$ vs $113 \%$ predicted, range $75-133 \%$ and $82-143 \%$ predicted, respectively, $\mathrm{p}<0.06)$. Although no subject sustained a fall in $\mathrm{FEV}_{1}$ sufficiently severe to require either premature termination of the procedure or bronchodilator therapy, temporary but significant falls in $\mathrm{FEV}_{1}$ were observed after sputum induction both in the normal control subjects (mean maximum fall in $\mathrm{FEV}_{1}$ from baseline $10.4 \%$, range $3-20 \%, \mathrm{p}<0.001$ ) and in the asymptomatic $\mathrm{HIV}$-seropositive patients (mean maximum fall in $\mathrm{FEV}_{1}$ from baseline $12.5 \%$, range $4-26 \%, \mathrm{p}<0.005$ )(table 3 and fig. 2). Although there was a trend towards larger falls in $\mathrm{FEV}_{1}$ in the HIV-seropositive group (table 3 and fig. 2), this did not reach statistical significance $(\mathrm{p}=0.16-0.65)$.

\section{Discussion}

This study has confirmed the usefulness and safety of induced sputum for investigating patients with suspected PCP, and has demonstrated significant falls both in FEV and oxygen saturation during the procedure. These falls in oxygen saturation have been shown to be greater, with lower peak and trough oxygen saturation values, in those patients with active PCP, despite any tendency to compensate for hypoxia by hyperventilation. Although the considerable overlap of saturation values between the PCP and non-PCP groups was sufficiently large to make this measurement unhelpful diagnostically, as found in an earlier study [5], it may be useful to identify further a subgroup of high-risk patients who should proceed to fibreoptic bronchoscopy. This is similar to the principle employed by Sмітн et al. [8], who found exerciseinduced oxygen desaturation to be a strong indicator of concurrent PCP. Although oxygen saturation levels in the symptomatic group fell below $90 \%$ in 38 of the 110 procedures $(35 \%)$, the severity of side-effects, such as breathlessness, associated with this hypoxia was very small, with only one patient requiring intermittent oxygen throughout the procedure. Furthermore, those patients whose saturation levels fell below $90 \%$ were observed to recover rapidly, as soon as the procedure was terminated. These patients would probably have been at greater risk of hypoxia had they undergone fibreoptic bronchoscopy, as a result of the combined effects of instrumentation, instillation of BAL fluid, and the respiratory depression caused by intravenous sedation.

In this study, chest radiography has been shown to be a useful predictor of clinical PCP, with a sensitivity of $79 \%$, a result which is in close agreement with that observed in other studies [9]. However, the clinical usefulness of radiography for diagnosing PCP was limited by the $17 \%$ of false-positive results, and, more importantly, by the $21 \%$ of false-negative results, which principally includes those patients with milder disease who are, presumably, also less likely to be diagnosed positive on sputum induction. Although a positive diagnosis of PCP still requires the use of either direct staining or molecular biological techniques [10], chest radiography will remain an important screening investigation to exclude patients unlikely to have PCP, so reducing the number of unnecessary induced sputum and bronchoscopy procedures. This screening application of chest radiography has also been shown, in theoretical studies, to be the most cost-effective approach to investigating patients with suspected PCP [11], and can be improved further by raising the sensitivity of sputum induction [12]. This sensitivity of sputum induction can range from 13-90\% in different institutions $[4,13,14]$, possibly reflecting varying levels of experience in both generating and analysing such specimens.

The fall in $\mathrm{FEV}_{1}$ documented in this study is a new finding which, although short in duration, was relatively severe in some individuals (up to $26 \%$ ), and may have been related to either increased bronchial reactivity in association with active lung disease, or, alternatively, residual lung damage from previous episodes of PCP. With improved long-term survival, this latter factor will become more important, as patients with one or more previous episodes of PCP are likely to represent an increasing proportion of the patient population undergoing this investigation. The observed trend towards greater falls in $\mathrm{FEV}_{1}$ in the HIV-seropositive group may be explained by a direct effect of HIV-infection on bronchial reactivity, or, alternatively, may reflect the presence of other, unidentified, subclinical pulmonary infections.

In conclusion, this study further demonstrates the safety and diagnostic value of sputum induction, but also highlights the propensity for certain individuals to develop arterial hypoxia and bronchoconstriction, and therefore the need for adequate medical supervision during the procedure.

Acknowledgements: The authors gratefully acknowledge the help of the physiotherapy department at Westminster Hospital. TRL is supported by a grant from the North West Thames RHA.

\section{References}

1. Murray JF, Mills J. Pulmonary infectious complications of human immunodeficiency virus infection. Part 2. Am Rev Respir Dis 1990; 141: 1582-1598.

2. Bennett CL, Gertler P, Guze PA, Garfinkle JB, Kanouse $\mathrm{DE}$, Greenfield S. The relation between resource use and in-hospital mortality for patients with acquired immunodeficiency syndrome-related Pneumocystis carinii pneumonia. Arch Intern Med 1990; 150 (7): 1447-1452.

3. Bigby TD, Margolskee D, Curtis JL, et al. The usefulness of induced sputum in the diagnosis of Pneumocystis carinii pneumonia in patients with the acquired immunodeficiency syndrome. Am Rev Respir Dis 1986; 133; 515-518.

4. Leigh TR, Parsons P, Hume C, Husain OAN, Gazzard BG, Collins JV. Sputum induction for diagnosis of Pneumocystis carinii pneumonia. Lancet 1989; 334: 205-206.

5. Miller RF, Buckland J, Semple SJG. Arterial desaturation in HIV positive patients undergoing sputum induction. Thorax 1991; 46: 449-451.

6. Nelson M, Bower M, Smith D, Gazzard BG. Lifethreatening complication of sputum induction. Lancet 1990; 335: 112. 
7. Smith DE, McLuckie A, Wyatt J, Gazzard B. Severe exercise hypoxaemia with normal or near normal X-rays: a feature of Pneumocystis carinii infection. Lancet 1988; 332: 1049-1051.

8. Smith DE, Forbes A, Davies S, Barton SE, Gazzard BG. Diagnosis of Pneumocystis carinii pneumonia in HIV antibody positive patients by simple out-patient assessments. Thorax 1992; 47: 1005-1009.

9. Millar AB, Mitchell DM. Noninvasive investigation of pulmonary disease in patients positive for the human immunodeficiency virus. Thorax 1990; 45: 57-61.

10. Leigh TR, Wakefield AE, Peters SE, Hopkin JM, Collins JV. Comparison of DNA amplification and immunofluorescence for detecting Pneumocystis carinii in patients receiving immunosuppressive therapy. Transplantation 1992; 54 (3): 468-470.
11. Freedberg KA, Tosteson AN, Cotton DJ, Goldman L. Optimal management strategies for HIV-infected patients who present with cough or dyspnoea; a cost-effectiveness analysis. J Gen Intern Med 1992; 7: 261-272.

12. Glenny RW, Pierson DJ. Cost reduction in diagnosing Pneumocystis carinii pneumonia. Sputum induction versus bronchoalveolar lavage as the initial diagnostic procedure. Am Rev Respir Dis 1992; 145: 1425-1428.

13. Miller RF, Kocjan G, Buckland J, Holton J, Malin A, Semple SJ. Sputum induction for the diagnosis of pulmonary disease in HIV positive patients. J Infect 1991; 23: 5-15.

14. Kirsch CM, Jensen WA, Kagawa FT, Azzi RL. Analysis of induced sputum for the diagnosis of recurrent Pneumocystis carinii pneumonia. Chest 1992; 102: 11521154. 